\title{
Afectaciones al equilibrio patrimonial derivadas del riesgo imprevisible
}

\section{Allocations to equity derivatives balancing risk of unpredictable}

\author{
Juan Pablo Leal Rico \\ Abogado, magíster en Derecho con énfasis en Derecho Empresarial y Contractual por la Universidad Santo Tomás \\ Bucaramanga. Docente y miembro del grupo de investigación Neoconstitucionalismo y Derecho de la Universidad \\ Santo Tomás Bucaramanga. \\ Correoelectrónico: juanplealr@hotmail.com
}

\begin{abstract}
Resumen
El acuerdo de voluntades permite que las partes vinculadas en una relación negocial satisfagan sus intereses, siempre que estos mantengan el equilibrio de las prestaciones recíprocas en un lenguaje de equivalencia, sin embargo, en la dinámica económica contemporánea se pueden presentar circunstancias imprevistas que no dependen de las partes y que lesionan sus intereses, generando una frustración convencional, la cual debe ser asumida con alternativa de superarse, mediante el restablecimiento del equilibrio económico y la adaptación del acuerdo ante las nuevas contingencias.
\end{abstract}

Palabras clave: Acuerdo de voluntades, equilibrio económico, relación negocial.

\begin{abstract}
Voluntary agreement can to parts at negocial relation meets theirs interest, when they keeps the equilibrium of reciprocal benefits in the equivalence language. However, in contemporary economic dynamic can be submit unexpected circumstances that no depend to parts and will be injured their interest. This generates conventional frustration and should be assumed with alternative overcome through the restore of economic equilibrium and agreement adapted to new contingencies.
\end{abstract}

Keywords: Voluntary agreement, economic balance, business relationship.

Résumé

L'accord volontaire permet aux parties associées dans une relation d'affaires répondent à leurs intérêts, à condition qu'ils maintiennent l'équilibre des avantages réciproques dans une équivalence de la langue, cependant, dans la dynamique économique contemporaine peut présenter des circonstances imprévues qui ne dépendent pas pièces et qui endommagent leurs intérêts, générant une frustration conventionnelle, qui doit être entreprise avec remplacement surmonter en rétablissant l'équilibre économique et l'adaptation en fonction des nouvelles éventualités.

Mots-clés: accord de volontés, équilibre économique, des relations d'affaires.

Recibido: 27 de mayo de 2015; Aprobado: 18 de julio de 2015 



\section{Afectaciones al equilibrio patrimonial derivadas del riesgo imprevisible*}

Juan Pablo Leal Rico

El contrato es como un organismo que está sujeto a las contingencias y variaciones de su ambiente y por lo tanto necesita ajustarse a los cambios de su realidad, adaptarse fisiológicamente al proceso evolutivo del entorno que lo rodea José Félix Chamie Gandur (2013)

\section{INTRODUCCIÓN}

En el estado de cosas actual, las relaciones jurídico-negociables buscan necesariamente el reporte de un beneficio equivalente para las partes, con una simetría elocuente entre los intereses y las obligaciones que se ejecutan. Sin embargo, siempre se reportan circunstancias superiores que las partes no pueden prever en el cumplimiento de sus prestaciones, lo cual dificulta su ejecución y convierten en desigual la relación negocial.

Como es sabido, el derecho como ciencia de estudio permanente, es el último engranaje que evoluciona en el constante movimiento de los elementos que constituyen el sistema orgánico normativo, entendiendo como componentes del mismo sistema a la persona, sus actos, sus intereses y su voluntad, cuando todo cambia y se evidencia el cambio, el derecho avanza.

En ese sentido, entender que frente al acuerdo de voluntades, pueden surgir cambios inesperados que alteren el cumplimiento de las obligaciones, convirtiendo lo cierto en imprevisible, permitirá precisar que los sujetos negociales no se encuentran exentos de circunstancias lesivas.

Estas circunstancias superiores a las partes han estado presentes como un fenómeno, conocido como dificultad sobrevenida o riesgo sobrevenido a través de la historia, caracterizado como una circunstancia imprevista que aparece con posterioridad a la celebración de un contrato y durante su ejecución, imposibilitando el cumplimiento de la manera como se pactó inicialmente.

* $\quad$ El presente texto se deriva del proyecto de investigación: “Afectaciones al equilibrio patrimonial como consecuencia del riesgo imprevisible", desarrollado por el autor, en el grupo de investigación Neo constitucionalismo y Derecho, Línea Organización y Actividad Empresarial. Universidad Santo Tomás Bucaramanga (Col.). 
El riesgo imprevisible o imprevisto también es conocido como imprevisión de los negocios, imprevistos contractuales o teoría de la imprevisión contractual y es entendido en un contexto global, como un fenómeno que se presenta durante la ejecución de los negocios civiles y mercantiles, afectándolos de no ejecución e imposibilidad material para cumplirlos, mediante elementos o circunstancias que eran imposible de ser previstas por las partes y consideradas como superiores y entendidas como un riesgo sobrevenido.

Durante muchos años, la doctrina y los estudiosos del derecho han tratado de identificar de qué manera es posible que durante la ejecución de un negocio jurídico se presenten circunstancias superiores y de fuerza mayor que deban ser entendidas como un riesgo que las partes difícilmente podrían prever, sin que dicha distinción se confunda con el caso fortuito o la fuerza mayor en sentido estricto y como eximente de responsabilidad.

Es sabido, que el riesgo imprevisible se presenta en los negocios jurídicos, mediante una manifestación de sorpresa y de manera inesperada, pero también es sabido que en las circunstancias actuales del derecho privado contemporáneo, difícilmente se escapan a las partes y a la naturaleza del negocio elementos o circunstancias que no se pueden prever, especialmente, la certeza de una economía de mercado, la seguridad jurídica en las transacciones mercantiles, la estabilidad de los negocios jurídicos, el conocimiento por lo más suficiente de las condiciones al tiempo de celebrar el contrato.

Sin embargo y a pesar de este conocimiento útil y necesario para las partes, existen fenómenos posibles, que se convierten en imprevisibles para las partes en un contrato tipo, como la posibilidad de una guerra que era posible en el contexto de la geopolítica global, pero sobrevenida para las partes en la celebración de un contrato de ejecución sucesiva, lo cual se convierte en un riesgo imprevisto, la posibilidad del fenómeno de la inflación en la economía interna de un país, el cual puede ser posible y previsible para el Estado, pero imprevista y por lo demás, sobrevenida para los particulares, solo para referir un par de ejemplos.

Adicionalmente debemos advertir, que la figura del riesgo imprevisto no pretende entenderse como un eximente de responsabilidad o una excusa para no cumplir entre las partes, al menos en principio, la idea fundamental es modificar el acuerdo lesionado por el riesgo imprevisto, presentando soluciones de mejora y evocando la idea del cumplimiento bajo nuevas condiciones, circunstancia que marca una distancia entre el riesgo imprevisto de la fuerza mayor y el caso fortuito.

\section{DE LA TEORÍA DEL RIESGO IMPREVISIBLE}

Las relaciones entre particulares se encuentran fundadas en el principio de la autonomía privada, el cual permite a los negociantes tener la facultad de crear la regla particular del derecho que puede disciplinar sus relaciones, este fenómeno también es conocido como autonomía de los particulares. 
Estas relaciones pretenden de manera particular crear relaciones jurídicas estables que faciliten el cumplimiento de obligaciones reciprocas, lo cual es altamente beneficioso para quienes las asumen, teniendo en cuenta que una de las principales reglas del derecho privado está basada en la creación de una relación conmutativa.

Sin embargo, en ocasiones este tipo de relaciones puede afectarse, a pesar de que exista una autorregulación de los involucrados a través de la autonomía privada, ocasionando una lesión en la base del negocio, en el cumplimiento de las obligaciones adquiridas y en las expectativas de sus intereses negociales, mediante circunstancias que van desde la voluntad de los negociantes, la ocurrencia de un caso fortuito o de una fuerza mayor, hasta la configuración de fenómenos imprevistos.

A través de la historia, partiendo desde sus primeras manifestaciones en Roma, cuando se permitía excusar de cumplir al sujeto negocial, si las circunstancias que dieron origen al negocio cambiaban, en relación con la imposibilidad para cumplir por hechos de fuerza; fenómeno conocido como un principio general del derecho: rebús sic stantibus.

Por su parte, la escuela de los canonistas jugó un papel importante, pues fueron ellos quienes contemplaron este fenómeno como una verdadera teoría digna de ser estudiada en la doctrina y bajo el entendido que las circunstancias sobrevenidas afectaban los contenidos del derecho canónico, acercando esta institución a los rangos de la equidad.

Igualmente, es importante el aporte de las diferentes escuelas del derecho, que posteriormente la convirtieron en teoría muy cercana a la filosofía, definiendo los elementos para su procedencia como la ocurrencia de hechos imprevistos y la excesiva onerosidad para las partes.

Más adelante se presentó la concepción de este fenómeno en términos de regla, en el entendido que evolucionó por los diferentes ordenamientos jurídicos como una norma y fue integrada en los códigos civiles de Europa, adicionando el hecho de que las partes exigían la posibilidad de revisar el contrato por medio de la jurisdicción, además de los aportes que desde la jurisprudencia se le asignaron a los cambios emblemáticos en términos de procedencia, conociéndose comúnmente como teoría de la imprevisión contractual.

En la actualidad instituciones jurídicas han asimilado este fenómeno y lo han incluido en su estructura y desarrollo, ejemplo de ello es la lex mercatoria, que ha sido útil para apreciar los usos, prácticas o costumbres y el interés de los Estados frente a la armonía del derecho en atención a la globalización de la economía y del mercado, permitiendo asimilar la imprevisión como circunstancias posibles en las relaciones entre estados y se inclina por las cláusulas (hardship) o la revisión del contrato.

Lo mismo ocurre con el Instituto para la Unificación del Derecho Privado (UNIDROIT), la Convención de las Naciones Unidas para los Contratos de Compraventa Internacional de Mercaderías, hecha en Viena el 11 de abril de 1980, en el artículo 79 prevé la exoneración de responsabilidad por incumplimiento de la obligación, probando 
que esa falta de cumplimiento se debe a un impedimento ajeno a su voluntad y si no cabía razonablemente esperar que tuviese en cuenta el impedimento en el momento de la celebración del contrato, que lo evitase o superase o que evitase o superase sus consecuencias.

Un aspecto importante en esta evolución es entender las directrices precisas sobre la fuerza obligatoria del contrato, la excesiva onerosidad que ha estado presente en la mayoría de las legislaciones continentales y la intención para armonizar y unificar disímiles culturas jurídicas, pero siempre buscando superar los conflictos, las antinomias, las incoherencias, la insuficiencia, la ambigüedad u oscuridad de las normas locales al respecto.

Siempre se busca que los fenómenos ocurridos sean compatibles con la realidad, procurando mecanismos idóneos para hacer frente a dichos cambios como la revisión del contrato, la renegociación, la modificación, y por consiguiente, la adaptación de las obligaciones contraídas.

Es entendido que dichos fenómenos acarrean un desequilibrio de las prestaciones recíprocas para las partes, que se conoce comúnmente como riesgo contractual, pero no se trata de la distribución de un riesgo, se trata de instrumentos que permitan superar las contingencias y garantizar el cumplimiento de las obligaciones a pesar de las nuevas contingencias.

Cuando nos ubicamos en la concepción de riesgo, necesariamente se evoca la idea de una amenaza de contingencia, la idea de una frustración, la sensación de un daño, la proximidad de una lesión, la posibilidad de fracaso, en todos estos ordenes, se materializa un efecto contractual denominado inejecución negocial, que no es otra cosa que la cesación en el cumplimiento de las obligaciones.

En ese sentido, es importante abarcar el estudio del riesgo contractual desde la dinámica de la imposibilidad para cumplir las obligaciones asumidas en un contrato y los efectos que la misma genera, en el marco de la normatividad expresada en el Código Civil.

Podemos afirmar, desde un criterio amplio, que la teoría del riesgo plantea la pregunta sobre la suerte de las obligaciones de las partes cuando la cosa que es objeto del contrato se pierde a consecuencia de un caso fortuito. La pregunta más pertinente frente a la ocurrencia de un riesgo en la relación negocial esta direccionada a formularse de la siguiente manera: ¿Qué suerte corren las obligaciones de un contrato cuando el objeto de este se pierde por un caso fortuito?

Pues bien, de una parte se ha establecido que la destrucción fortuita de la cosa siempre extingue la obligación que tenía por objeto esa cosa. Y por otra parte, respecto de la obligación de la otra parte, caben dos posibilidades dependiendo si el riesgo surge de parte del deudor o del acreedor:

Si el riesgo es del deudor:

- Si estaba obligado a dar la cosa que se destruyó fortuitamente, entonces la obligación del acreedor se extingue también. 
- Si todavía no cumplía con su prestación, nada debe hacer, y

- Si ya la cumplió tiene derecho a ser restituido.

Si el riesgo es del acreedor:

- Frente a la destrucción fortuita de la cosa, su obligación sigue en pie, debe cumplirla si se encuentra pendiente o

- $\quad$ si ya la cumplió no puede ser restituido.

Por otro lado, el Código Civil colombiano establece que existe una forma de extinción de las obligaciones derivada de la pérdida de la cosa que se debe y reza literalmente:

Artículo 1729: Cuando el cuerpo cierto que se debe perece, o porque se destruye, o porque deja de estar en el comercio, o porque desaparece y se ignora si existe, se extingue la obligación; salvas empero las excepciones de los artículos subsiguientes" (Congreso, 1887).

En ese sentido, el común denominador de la relación negocial afectada por pérdida de la cosa que se debe, genera que uno de los contratantes se encuentra en la imposibilidad de cumplir su obligación, en virtud de un acontecimiento independiente de la voluntad, el otro contratante se encuentra liberado de su obligación.

Por lo anterior, el estudio de los efectos de la imposibilidad de cumplimiento de las obligaciones recíprocas de las partes origina la teoría de los riesgos, entendiendo adicionalmente que cuando una de las partes no cumple con su obligación y cuando es responsable de ese incumplimiento, se concibe que, a título de sanción excusa a la otra parte de cumplir con su prestación, lo permitirá la resolución judicial.

Lo anterior se diferencia de la teoría del riesgo imprevisible en el entendido que la contingencia viene acompañada de circunstancias imprevistas, especialmente cuando existe excesiva onerosidad que altera fundamentalmente el equilibrio del contrato, de donde se pueden caracterizar las siguientes razones:

1) Que el costo de la prestación a cargo de una de las partes se ha incrementado, o porque el valor de la prestación que una parte recibe ha disminuido.

2) Que dichos eventos acontecen o llegan a ser conocidos por la parte en desventaja después de la celebración del contrato;

3) Que los eventos no pudieron ser razonablemente tenidos en cuenta por la parte en desventaja en el momento de celebrarse el contrato;

4) Que los eventos escapan al control de la parte en desventaja; y

5) Que el riesgo de tales eventos no fue asumido por la parte en desventaja.

En nuestra legislación, específicamente en el artículo 868 del Código de Comercio se entiende que los elementos más importantes que facilitan la procedencia y existencia de la imprevisión contractual derivada del riesgo imprevisible de los contratos, se identifican cuando se presentan de la siguiente manera:

1) Que se trate de contratos de ejecución continuada sucesiva o a término, por cuanto la imprevisión supone la duración del contrato en el tiempo. 
2) Que con posterioridad a la celebración del contrato se presente un acontecimiento que racionalmente no haya sido previsto por los contratantes, es decir, un acontecimiento que se encuentre por fuera del alea normal del contrato.

3) Que el acontecimiento imprevisto altere notablemente las condiciones económicas previstas en el momento de contratar, en tal forma que el contrato que en un principio fue sinalagmático deje de serlo.

Solo si se logran incluir y dinamizar los elementos enunciados del riesgo imprevisto y los elementos de procedencia de la denominada teoría de la imprevisión contractual, como una mixtura jurídica de procedencia que permita hablar de imposibilidad para cumplir por el hecho superior, sobrevenido, imprevisto y oneroso.

Sea cual fuere el efecto que genera la teoría, la imprevisión debe formularse en instancia, probarse y debatirse ampliamente, consistiendo en un remedio de aplicación extraordinaria y estableciendo con creces que las nuevas circunstancias exceden en mucho las previsiones que racionalmente pueden hacerse al tiempo de contratar, y que esos acontecimientos son de tal carácter o gravedad que hacen intolerable la carga de la obligación para una de las partes, a más que injusta y desorbitante ante las nuevas circunstancias.

Todo esto, como es obvio, requiere la concurrencia de un conjunto de hechos complejos y variados que deben alegarse, especialmente aquellos que prueban la pérdida del equilibrio económico del contrato, con el propósito de reorientar las secuelas de la lesión y proceder en términos de la equidad a recuperar los daños generados.

Esta concepción debe tener en cuenta los presupuestos del principio de equidad, toda vez que los mismos son necesarios para identificar la consolidación de la teoría de la imprevisión en los contratos y ante esta circunstancia que bordea la práctica de la misma se hace posible su presentación a través de la equidad, según el tratadista Fernando Vélez, frente e a la resolución del contrato siempre se acompaña el principio de equidad, que justifica la autorización que el legislador hace al contratante cumplido para desligarse del vínculo que lo une al contratante incumplido (Palacios, 2009).

La resolución judicial es una aplicación a la idea de causa, como una manifestación del principio de equivalencia de las prestaciones en el contrato o un instrumento técnico destinado a asegurar a la vez el equilibrio económico, sus fines prácticos y su ejecución de buena fe, la idea profunda es siempre la misma, la justificación legal de la idea de justicia contractual.

La regla de que los contratos deben ejecutarse de buena fe, parte de un criterio universal y de carácter general y de una manera de revisar las potestades especiales de los contratantes, esto se logra protegiendo el resultado económico que persiga el contratante, es decir, utilizando la ecuación financiera del contrato. 


\section{DEL EQUILIBRIO PATRIMONIAL DE LOS CONTRATOS}

En la celebración de convenciones, acuerdos o contratos, existen propósitos que irradian la celebración, la ejecución y el cumplimiento, que deben estar acompañados de postulados garantizadores para su ejecución, así como nadie contrata para incumplir, tampoco lo hace para fracasar, y en se sentido, es importante revisar al interior de cada contrato el postulado que permite su nacimiento, la razón de ser, su causa, el motivo que lo induce a la celebración.

De todos los ejes irradiadores que potencializan la creación del contrato, son los principios de la contratación, los elementos idóneos para determinar sus alcances, con el propósito de disciplinar, encauzar o simplemente completar los fines últimos de la celebración y, sobre todo, el elemento conmutativo de las relaciones recíprocas.

Uno de los principios de mayor relevancia en el sistema del derecho privado contemporáneo, que se hace evidente en las relaciones que pretenden la creación de contratos, se denomina: equilibrio patrimonial.

Se entiende que los contratos deben mantener una equivalencia recíproca en sus obligaciones, para evitar lesiones superiores que afecten gravemente la ejecución de los acuerdos y es allí donde el principio de equilibrio patrimonial mantiene las cargas de las partes en igualdad de condiciones, evitando entre otros aspectos dañinas figuras como las que se enuncian a continuación:

- La lesión enorme desarrollada en el artículo 1946 del Código Civil.

- La ineficacia de prestaciones irrisorias, interpretada en el artículo 872 del Código de Comercio.

- La ineficacia de la compraventa por precio irrisorio desarrollada en el artículo 920 Código de Comercio.

- La inexistencia parcial de la cosa debida desarrollada en el artículo 1870 del Código Civil.

- La evicción parcial, como obligación de saneamiento del vendedor cuando la cosa entregada tiene un vicio jurídico desarrollado en el artículo 1911 del Código Civil.

Lo anterior denota que el carácter patrimonial va inmerso en los contratos en relación con los intereses que se crean y se extinguen, entendiendo que los contratos se derivan de este principio y por esta razón, cuando el equilibrio económico del contrato se afecta o simplemente no se hace presente, se generan problemas de orden público importantes, incluso en materia de responsabilidad civil contractual y extracontractual, cuando se trate de resarcir los perjuicios que se presenten a raíz de la inejecución de un contrato.

Ahora bien, lo importante es que la causal que lesiona el equilibrio económico del contrato, sea eminentemente ajena a las partes vinculadas en la negociación, entendiendo que las mismas desean recuperar o restablecer las causas que lo afectan 
de manera voluntaria, siempre que no sean ellas las causantes de la frustración que se genera.

Todas las prestaciones que se derivan de un contrato tienen un interés económico y patrimonial que permite que los intereses de la negociación funcionen, adicionalmente los mismos generan en el contrato una expectativa de cumplimiento recíproco, toda vez que el cumplimiento de las obligaciones está atado a la satisfacción de los intereses y estos no pueden ser afectados en su utilidad.

Por otra parte, podríamos inferir que el desequilibrio económico del contrato ocurre cuando la igualdad o la equivalencia entre derechos y obligaciones surgidas al momento de proponer o de contratar, según sea el caso, se altera. "Si se rompe el equilibrio por causas no imputables a quien resulte afectado, las partes deben adoptar las medidas necesarias para su restablecimiento" (Procuraduría, 2012).

Una de las principales preocupaciones que puede surgir cuando el equilibrio económico del contrato se lesiona, es la pérdida de capacidad negocial o de cumplimiento que pueda sufrir la parte afectada, más aún, cuando dicha afectación que pudiendo cumplirse no se cumple, genera una onerosidad excesiva a quien no desea excusarse de cumplir.

Por otro lado, incluso el contrato afectado en la prestación económica puede terminarse o correr el riesgo de terminarse, generando un efecto natural en los contratos, en el entendido, que si una de las partes no cumple sus obligaciones independientemente de la causal para no hacerlo, el resultado inmediato será perder las expectativas de ejecución que se plantearon en el inicio del contrato y que fueron la causa de la negociación, ya sea resolviendo el acuerdo mediante la terminación.

En el entendido de su inejecución, lo natural sería aplicar la resolución por incumplimiento de contrato, que opera cuando por una causa ajena al deudor, la prestación se torna imposible, entonces aunque incumple, queda liberado por cuanto su obligación se extingue.

Sin embargo, si las dos partes, por efecto del mismo contrato, estaban obligadas correlativamente, la liberación de uno de los deudores como consecuencia de un caso de fuerza mayor deja abierta otra cuestión: determinar si la otra parte queda obligada a cumplir su obligación. A esta hipótesis se le conoce como imposibilidad subjetiva de cumplir la prestación o excesiva onerosidad sobrevenida.

Así las cosas, si en el intervalo que separa la conclusión de un contrato y el de su ejecución, se produce un acontecimiento imprevisto que altera notoriamente las condiciones económicas previstas en el momento de contratar, en forma que uno de los contratantes resulta notoriamente perjudicado, tendrá derecho el lesionado de instaurar alguna acción o recurso para que los jueces revisen el contrato a fin de hacer desaparecer la lesión.

El Código de Comercio en el artículo 868 contiene unos elementos de notoria trascendencia para entender la imprevisión como un fenómeno que puede ser entendido en términos de regla al ser presentado como norma, veamos: 
Art. 868.- Cuando circunstancias, extraordinarias, imprevistas o imprevisibles, posteriores a la celebración de un contrato de ejecución sucesiva, periódica o diferida, alteren o agraven la prestación de futuro cumplimiento a cargo de una de las partes, en grado tal que le resulte excesivamente onerosa, podrá ésta pedir su revisión.

El juez procederá a examinar las circunstancias que hayan alterado las bases del contrato y ordenará, si ello es posible, los reajustes que la equidad indique; en caso contrario, el juez decretará la terminación del contrato.

Esta regla no se aplicará a los contratos aleatorios ni a los de ejecución instantánea (Código de Comercio, 1887).

Esta es la única norma en nuestro ordenamiento jurídico que, de manera clara, permite una interpretación adecuada a las afectaciones jurídicas que se generan en un contrato lesionando el equilibrio patrimonial y la concepción conmutativa de las prestaciones recíprocas.

Indudablemente, lo anterior se presenta como una norma que sirve para adecuar los sucesos imprevistos en los contratos, solicitando al juez que plantee una posible solución a través de la revisión del contrato.

Si el acontecimiento que se presenta durante la ejecución del contrato afecta en tal medida el cumplimiento de las obligaciones recíprocas, especialmente atacando su elemento económico, resulta improcedente pretender la ejecución del mismo, cuando las circunstancias varían lesionando la estabilidad económica de una de la partes, el equilibrio económico afectado por imprevisión es la causa más común de terminación de la relación negocial, pues nadie que ha pactado determinada prestación, está obligado a cumplirla si las circunstancias variaron en tal sentido, que cumpliendo generaría en su patrimonio una disminución desproporcionada e inconveniente.

Sin embargo, y una vez estudiados los fenómenos en que se puede romper el equilibrio patrimonial en una relación negocial, lo importante es identificar hasta qué punto dicha compensación amerita la continuación mediante una revisión equivalente del contrato, o definitivamente su terminación como medio para evitar un desequilibrio mayor o para recuperarlo.

La tradición en el derecho continental sugiere que el desequilibrio económico del contrato, ocurrido por circunstancias ajenas o superiores a los sujetos negociales, genera un efecto directo en la terminación, más no en la preservación del acuerdo, pues la mera ocurrencia del efecto desequilibrante acarrea un incumplimiento del acuerdo y genera en los contratantes tan solo una expectativa de perseverar si las circunstancias cambian.

Cuando las condiciones económicas pactadas en el contrato fueren alteradas en perjuicio de una de las partes por causas no imputables a esta, ocurridas durante la ejecución del contrato, se impone la obligación de restablecer el equilibrio financiero. 
El equilibrio económico se ve afectado por tres causas:

1) actos o hechos imputables a la administración contratante, referidos, por ejemplo, al pago inoportuno de las cuentas de cobro presentadas por el contratista, o a la falta de oportunidad en la aprobación de la documentación necesaria para el desarrollo del contrato, tal como diseños o planos de las obras por realizar;

2) actos de la administración ya no como contratante sino como Estado, analizados a luz de la teoría del hecho del príncipe; y

3) actos o hechos ajenos a las partes del contrato, o factores sobrevinientes, abordados generalmente desde la perspectiva de la teoría de la imprevisión (Consejo de Estado, 2011).

De tal suerte, que la falta del equilibrio económico del contrato puede desembocar en terminación de la relación negocial y no en la ejecución, circunstancia de por sí, inconveniente y contradictoria con los principios que irradian la relación contractual entre particulares, especialmente, el de preservación, el de seriedad contractual y el de buena fe, este último en la mayoría de las relaciones negociales.

En el aspecto económico del contrato:

las partes al momento de la celebración determinan la economía del mismo y se debe examinar cuál será el sacrificio o utilidad que recibirán si se mantiene inalterada la idea inicialmente pactada. Es por ello que la ley solo tiene en cuenta las prestaciones excesivamente onerosas, aquellas que no entran en el alea normal del contrato, pues el contratante asume las diferencias normales en el tipo de actividad que desarrolla (Barrios, 2007).

Como característica principal de los contratos el principio de equilibrio patrimonial tiene alta resonancia en numerosos aspectos de la normativa contractual, y por ello a modo de ejemplo se tiene que "todas las prestaciones que se derivan de ellos tienen una connotación patrimonial y, en particular, dineraria, de tal suerte que aún las obligaciones de no hacer pueden traducirse en obligaciones de dinero" (Bohórquez, 2013).

Siendo consientes con los intereses del contrato, con los propósitos y el interés económico de los sujetos negociales, puede entenderse que las partes son coherentes si ante las contingencias derivadas del riesgo imprevisible acuden a los principios de la contratación privada, especialmente:
a. La autonomía privada.
b. La seriedad contractual.
c. La tutela de la confianza.
d. La buena fe.
e. El equilibrio de las prestaciones.
f. El de claridad y sagacidad. 
g. El principio de solidaridad,

h. y sobre todo, el principio de preservación.

Si los principios no se activan, difícilmente podrá rescatarse el contrato, la naturaleza jurídica del riesgo imprevisible no descarta la posibilidad de cumplir y por lo tanto resultaría obtuso con el contrato si las partes no aprovechan esta situación, distinto sería que no lo aplicaran si la figura misma lo impidiera, pues dicho sea de paso, sería innecesario, incluso analizar dicha posibilidad, que aunque remota en ocasiones las partes la contemplan.

\section{Afectaciones al equilibrio patrimonial derivadas del riesgo imprevisible}

En el marco de la teoría general de las obligaciones, existen consecuencias jurídicas específicas, entendidas en nuestro Código Civil como efectos de las obligaciones, enunciados en los artículos 1602, al 1613 y dentro de los cuales se destacan fenómenos que diferencian la teoría del riesgo imprevisto en relación con las consecuencias jurídicas que se desprenden de toda relación negocial.

En el marco de dichos efectos, se pueden destacar, entre otros:

\section{ARTÍCULO 1602. LOS CONTRATOS SON LEY PARA LAS PARTES.}

Todo contrato legalmente celebrado es una ley para los contratantes, y no puede ser invalidado sino por su consentimiento mutuo o por causas legales" (Congreso, 1887).

Lo anterior significa que un acuerdo afectado por riesgo puede modificarse con la anuencia expresa, el acuerdo mutuo y la voluntad inequívoca de las partes de dejar sin efecto el contrato cuando el mismo no se puede cumplir en los términos iniciales.

1. ARTÍCULO 1603. EJECUCIÓN DE BUENA FE. Los contratos deben ejecutarse de buena fe, y por consiguiente obligan no solo a lo que en ellos se expresa, sino a todas las cosas que emanan precisamente de la naturaleza de la obligación, o que por ley pertenecen a ella (Congreso, 1887).

Podríamos afirmar que la buena fe, protege a las partes de la inejecución derivada del riesgo imprevisto, en el entendido que obran esperando cumplir no excusándose de hacerlo, pero sobre todo entendiendo que el riesgo haya sido probado

1. ARTÍCULO 1604. RESPONSABILIDAD DEL DEUDOR. El deudor no es responsable sino de la culpa lata en los contratos que por su naturaleza solo son útiles al acreedor; es responsable de la leve en los contratos que se hacen para beneficio recíproco de las partes; y de la levísima en los contratos en que el deudor es el único que reporta beneficio

El deudor no es responsable del caso fortuito, a menos que se haya constituido en mora (siendo el caso fortuito de aquellos que no hubieran 
dañado a la cosa debida, si hubiese sido entregado al acreedor), o que el caso fortuito haya sobrevenido por su culpa.

La prueba de la diligencia o cuidado incumbe al que ha debido emplearlo; la prueba del caso fortuito al que lo alega.

Todo lo cual, sin embargo, se entiende sin perjuicio de las disposiciones especiales de las leyes, y de las estipulaciones expresas de las partes (Congreso, 1887).

En ese aspecto de la normatividad, podemos afirmar que de presentarse un riesgo imprevisto, la teoría de la responsabilidad por culpa no se tiene en cuenta, ya que la presencia del riesgo no se compadece con la diligencia y cuidado, pues como lo hemos dicho, el riesgo es imprevisible, más allá del cuidado necesario que puede emplearse por los sujetos negociales, y las dos posiciones jurídicas son excluyentes, pues en la culpa debo hablar necesariamente de previsibilidad.

Si bien el caso fortuito encarna la idea de los hechos superiores a la voluntad de las partes que afectan el acuerdo, también es posible que se asuma el riesgo imprevisto como una fuerza mayor si entendemos el elemento de superioridad e imposibilidad para cumplir, pero tendríamos que distanciarnos de la figura sí entendemos que la misma procura el eximente o la excusa de cumplimiento.

Si bien, por ejemplo un terremoto, es una circunstancia de la naturaleza, que genera efectos en el derecho y que se entiende como imprevisible, podríamos decir que exime de cumplir a las partes, pero si la voluntad de estas es conservar o preservar en el acuerdo, podríamos advertir que se pretende modificar las condiciones de cumplimiento conservando el pacto a pesar de la lesión.

El elemento del caso fortuito es la imposibilidad material y definitiva para cumplir, mientras que el riesgo imprevisto o la imprevisión contractual es asumida con la posibilidad de ser amparada mediante la modificación voluntaria de las partes.

1. ARTÍCULO 1605. OBLIGACIÓN DE DAR. La obligación de dar contiene la de entregar la cosa; y si ésta es una especie o cuerpo cierto, contiene, además, la de conservarla hasta la entrega, so pena de pagar los perjuicios al acreedor que no se ha constituido en mora de recibir (Congreso, 1887).

2. ARTÍCULO 1606. OBLIGACIÓN DE CONSERVAR LA COSA. La obligación de conservar la cosa exige que se emplee en su custodia el debido cuidado (Congreso, 1887).

En estos dos aspectos, la teoría del riesgo se aleja de la obligación de conservar, ya que la circunstancia imprevista puede en algunos casos ocasionar el deterioro o la pérdida del bien que se pretende entregar: 
3. ARTÍCULO 1607. RIESGOS EN LA DEUDA DE CUERPO CIERTO. El riesgo del cuerpo cierto cuya entrega se deba, es siempre a cargo del acreedor; salvo que el deudor se constituya en mora de efectuarla, o que se haya comprometido a entregar una misma cosa a dos o más personas por obligaciones distintas; en cualquiera de estos casos será a cargo del deudor el riesgo de la cosa hasta su entrega (Congreso, 1887).

Aquí el fenómeno toma mayor relevancia, ya que el riesgo presentado puede ser imprevisto y se aplicarían las excepciones desarrolladas en el artículo:

4. ARTÍCULO 1613. INDEMNIZACIÓN DE PERJUICIOS. La indemnización de perjuicios comprende el daño emergente y lucro cesante, ya provenga de no haberse cumplido la obligación, o de haberse cumplido imperfectamente, o de haberse retardado el cumplimiento. Exceptúense los casos en que la ley la limita expresamente al daño emergente (Congreso, 1887).

5. ARTÍCULO 1614. DAÑO EMERGENTE Y LUCRO CESANTE. Entiéndase por daño emergente el perjuicio o la pérdida que proviene de no haberse cumplido la obligación o de haberse cumplido imperfectamente, o de haberse retardado su cumplimiento; y por lucro cesante, la ganancia o provecho que deja de reportarse a consecuencia de no haberse cumplido la obligación, o cumplido imperfectamente, o retardado su cumplimiento (Congreso, 1887).

Este efecto puede suspenderse en el tiempo, si se logra entender que el riesgo no se causa por la mora en el cumplimiento de la obligación, en la negación para cumplir, en el retardo o en la culpa del deudor, se trata de una imposibilidad para cumplir que si bien genera mora, la misma no se causa por la voluntad del deudor, lo cual la distancia de la responsabilidad por culpa y la indemnización quedaría sin efecto.

Más aún, si entendemos que el riesgo se asume como imposibilidad no como negación para la ejecución de las obligaciones.

Ahora bien, entender el comportamiento de estos efectos facilita que se permita diferenciar las consecuencias más relevantes que pueden presentarse frente a la ocurrencia de un riesgo imprevisible ante una relación negocial, que entre otros aspectos se rescatan las siguientes:

- El riesgo imprevisible, genera imposibilidad para cumplir las obligaciones.

- El riesgo imprevisible, no exime de la responsabilidad de cumplir, aunque se haya perdido la cosa que se debe.

- El riesgo imprevisible no extingue la obligación.

- El riesgo imprevisible altera la base negocial del acuerdo tornándolo difícil, no imposible. 
- El riesgo imprevisible no exonera de cumplir, genera la hipótesis de cumplir bajo nuevas circunstancias.

Estas consecuencias que se presentan como las más concurrentes, permiten identificar el riesgo imprevisible como una forma de imprevisión contractual, generando la posibilidad de que las partes adecuen o se adapten a las nuevas circunstancias para cumplir de otra manera con las obligaciones pactadas, esto es, que las mismas muten a nuevas circunstancias que faciliten el cumplimiento.

No se trata, entonces, de excusarse de cumplir, ni de liberarse de la obligación como consecuencia del riesgo imprevisible, tampoco de extinguir la obligación baja los fenómenos de la compensación, la condonación o la novación, se trata de que la obligación subsista pero se cumpla en otra forma, utilizando las modalidades obligaciones y sobre todo permitiendo a las partes renegociar las condiciones para cumplir.

La naturaleza jurídica del riesgo imprevisible, así como una de sus consecuencias, es la ocurrencia de un hecho sobrevenido motivado por la fuerza mayor, solo que su efecto sobre la obligación no es la imposibilidad absoluta, sino más bien la excesiva onerosidad que implica cumplirla.

En ese sentido, se hace necesario que frente a las nuevas circunstancias, las partes logren en definitiva cumplir las obligaciones y la ejecución del contrato; a pesar, incluso, de que la fuerza mayor haya generado un desequilibrio económico en el contrato, entendiendo que la realidad ha cambiado y el contrato debe adaptarse, evolucionar con esa realidad.

Por supuesto que la posibilidad de preservación depende en absoluto de la autonomía de las partes, de su libertad para disponer de los derechos patrimoniales que se debaten; de no existir la suficiente voluntad de las partes para solucionar las contingencias, rescatar la relación negocial y perseverar en el negocio, difícilmente la evolución del contrato con su respectiva adaptación puede ser posible.

Así las cosas, y teniendo en cuenta que el hecho imprevisto genera la posibilidad de revisión, basado en que el riesgo imprevisible no extingue la obligación y aunque la torna difícil no la vuelve imposible, la idea inicial de conservación sería la renegociación por el hecho de producirse un cambio considerado con base en el negocio.

Precisamente la renegociación es un deber de las partes, pero deben existir unos presupuestos para hacerlo, y estos son variados de acuerdo con el amplio margen de la autonomía privada, igualmente las condiciones bajo las cuales las partes se obligan a renegociar pueden referirse a todos los aspectos del contrato, bien sean de orden financiero, de utilidades, de transferencia y reinversión de beneficios o aquellos relacionados con el control de aspectos particulares de la ejecución de las prestaciones (Mazeaud, s.f.).

Sin embargo, las partes incluso pueden en el contrato incluir una cláusula que las obligue a renegociar las condiciones del acuerdo para cumplir de mejor manera de 
presentarse un hecho imprevisto que genere un riesgo imprevisible, a dicha cláusula se le conoce como cláusula de imprevisión o cláusula de renegociación, algunos tratadistas también la distinguen como la cláusula de revisión o de preservación.

Esto significa que las partes pueden prever, no la ocurrencia del hecho jurídico que los afecta, sino la eventual renegociación de presentarse este último y así no dejarían al devenir de las circunstancias futuras una posible revisión de los acuerdos. Incluso las partes podrían redactarla en términos condicionales, según los cuales podría sujetarse la renegociación solo si el hecho imprevisto afecta el equilibrio económico del contrato.

El contenido de la cláusula debe determinar los pactos conforme a los cuales se prevé la renegociación, para determinar qué aspectos pueden y deben estar sujetos a revisión y aunque el deber de negociar no es de carácter obligatorio en sentido estricto, puede generar la idea de recuperación del contrato en coherencia con los postulados del derecho privado, pues nadie contrata para fracasar.

Si la cláusula se pacta con una indudable naturaleza de tipo accidental, las partes deben tener en cuenta los siguientes aspectos que permitirían pensar que se trata ciertamente de recuperarse de la lesión:

a. Que las partes quisieron prever solamente la posibilidad de entablar la renegociación en términos de simple eventualidad en cuyo caso desaparece el carácter jurídico del pacto.

b. Si las lagunas de la cláusula pueden ser colmadas respecto de circunstancias tales como la naturaleza del contrato o los usos adoptados por las partes.

c. La conducta sucesiva de una de las partes que señale la intención común de renegociar o bien los criterios del acuerdo asumido.

Un elemento importante que se debe tener en cuenta para que se pueda evidenciar que las partes pretenden materializar el deber de negociar, es un entendimiento coherente entre ellas, sobre la oportunidad de modificar el contrato, para que la iniciativa de promover el inicio de las nuevas negociaciones y de la invitación a negociar de una parte deriva el deber de replicar con claridad por la otra señalando su posición al respecto.

Teniendo certeza de lo anterior, es importante que se avance en el siguiente paso que propende por la conservación del contrato afectado por lesión derivada del riesgo imprevisible y que no ha generado eximente para cumplir y aún mantiene el vínculo negocial entre las partes, ya sea por su voluntad de mantenerlo o porque se pactó la cláusula que los obliga a permanecer.

De tal suerte, que una vez inicie la etapa de renegociación, esta también debe estar acompañada del principio de la buena fe, pues no se puede renegociar sobre lo imposible, lo ilícito o lo inconveniente, ya que dicha hipótesis tornaría al negocio en fallido, improcedente, inoperante o nulo y por consiguiente se perdería el fin último de la renegociación, que conlleva conservar el acuerdo, el mismo acuerdo, pero adaptado a las nuevas circunstancias para su cumplimiento. 
Así las cosas, se debe realizar una manifestación explícita de la voluntad donde se exteriorice el deber de renegociar, pero sobre todo se tenga en cuenta los siguientes puntos de notoria importancia que son propuestos por el doctor José Félix Chamie Gandur, en su teoría de adaptación del contrato, veamos:

a. Mantener el marco de la renegociación.

b. Respetar las otras disposiciones del contrato.

c. Tener en cuenta la práctica contractual prioritaria entre las partes.

d. Procurar un esfuerzo real para gestionar el acuerdo.

e. Prestar atención a los intereses de la contraparte.

f. Producir información relevante para la adaptación.

g. Mostrar su sincera voluntad de compromiso.

h. Mantener una conducta flexible en la negociación.

i. Buscar las soluciones de reajuste.

j. Hacer concretas y razonables sugerencias.

k. Evitar precipitadas sugerencias de reajuste.

1. Dar las razones apropiadas para justificar las propias sugerencias del reajuste.

m. Obtener ayuda en difíciles procesos de acuerdo.

n. Responder oportunamente las respuestas del reajuste.

o. Hacer esfuerzos por mantener la relación negocial.

p. Evitar cualquier ventaja injusta o detrimento para las partes (Chamie, 2013).

Si se lo logra una renegociación que asuma estas sugerencias, y el marco del negocio vuelva a su cauce o se oriente con relación a las nuevas circunstancias, podríamos decir entonces que los sujetos negociales se encuentran en dirección de recuperar el equilibrio económico del contrato, y por consiguiente el riesgo imprevisible pasa a ser resuelto con la ejecución de las obligaciones adaptadas mediante el acuerdo.

Es indudable que la mayor preocupación que puede surgir después de la negociación es que las nuevas formas de cumplir no se materialicen, imaginando que estas fueron renegociadas bajo supuestos de modalidad, esto es, mediante la creación de obligaciones condicionales o de plazo, que se sustentan en las hipótesis de hechos futuros ciertos e inciertos.

Pues si la condición no se cumple o el plazo se vence sin el cumplimiento previo de la obligación materia de negociación, entonces podríamos estar frente a un nuevo fracaso que se presenta, ya no de la circunstancia imprevista, sino de la inejecución del acuerdo, evento que nos pondría en la definitiva terminación del acuerdo por resolución, sumando las indemnizaciones de ley.

El anterior es un escenario que puede ser evitado con el buen ejercicio de las obligaciones pactadas que han permitido en medio de la renegociación que el contrato se preserve; pero no es el simple hecho de puntualizar en nuevas hipótesis para cumplir, también bajo el enunciado que dichas hipótesis permitan en la práctica un verdadero cumplimiento, con la adecuada formulación de obligaciones posibles. 
En el derecho civil de las obligaciones existen una serie de hipótesis que han sido creadas por el legislador para facilitar en todos los casos el cumplimiento de la prestación de obligaciones alternativas, solidarias, divisibles, condicionales, a plazo, con cláusula penal, estos son algunos ejemplos de donde las partes pueden tomar la sabia decisión que permite una verdadera recuperación del equilibrio perdido por el hecho imprevisto.

Lo anterior nos permitirá entender que el contrato lesionado por imprevisión puede adaptase mediante la renegociación de las condiciones y por consiguiente preservarlo, siempre que la continuidad logre restablecer el equilibrio de las prestaciones recíprocas.

\section{REFERENCIAS}

Arrubla, J. (2012). Contratos mercantiles, contratos típicos. Bogotá: Legis Editores S.A.

Barbosa et al. (1992). La teoría de la imprevisión en el derecho civil colombiano. Bogotá: Ediciones Jurídicas Radar.

Barrios et al. (s.f.). Desarrollo teórico y jurisprudencial de la teoría de la imprevisión y su incidencia en la ecuación económico-financiera en los contratos públicos en Colombia. Medellín.

Bonivento, J. (2005). Los principales contratos civiles y comerciales. Bogotá: Librería Ediciones del Profesional LTDA.

Cabanellas, G. (2003). Diccionario enciclopédico de derecho usual. Bueno Aires: Edición Editorial Heliasta.

Chamie, J. (2013). La adaptación del contrato por eventos sobrevenidos. Bogotá: Universidad Externado de Colombia.

Colin, C. (1960). Curso elemental de derecho civil. Teoría general de las obligaciones. Madrid: Instituto Editorial Reus.

Congreso de la República de Colombia. (1887). Código civil, Ley 57 de 1887. Bogotá: Legis Editores S.A.

Consejo de Estado de Colombia. (2011). Sentencia del 7 de marzo de 2011. M.P.: Olga Mélida Valle de la Hoz.

Corte Constitucional de Colombia. (1998). Sentencia C-252 de 1998. M. P.: Carmenza Isaza de Gómez.

Corte Constitucional de Colombia. (2011). Sentencia T - 837 de 2011. M.P.: Gabriel Eduardo Mendoza Martelo.

Corte Suprema de Justicia de Colombia. (1936). Sentencia del 29 de octubre de 1936. M.P.: William Namén Vargas.

Corte Suprema de Justicia de Colombia. (1937). Sentencia del 25 de febrero de 1937. M.P.: Jorge Arango Mejía. 
Corte Suprema de Justicia de Colombia. (1983). Sentencia de marzo 24 de 1983. M. P.: Alberto Ospina Botero.

Daza, M. (s.f.). Aplicación de los principios contractuales a los contratos mercantiles. Bogotá.

De la Maza, L. (1938). De la teoría de la imprevisión. Bogotá.

Enrique, R. (2003.). Distribución de los riesgos en la contratación administrativa. Bogotá.

Mazeaud et al. (s.f). Lecciones de derecho civil. Buenos Aires: Ediciones Jurídicas Europa-América.

Planiol et al. (1936). Tratado teórico y práctico del derecho civil francés. La Habana: Editorial Cultural.

Presidencia de la República de Colombia. (1971). Código de comercio, Decreto 410 de 1971. Bogotá: Legis Editores S.A.

Priore, J. (1969). Resolución de los contratos civiles por incumplimiento. Montevideo: Librería Editorial Amalio M. Fernández.

Procuraduría General de la Nación. (2012). Concepto número 002 de 2012. M.P.: Olga Mélida Valle de la Hoz.

Rengifo, R. (1981). Contratos comerciales. Bogotá: Colección Pequeño Foro.

Terraza, J. (1951). Modificación y resolución de los contratos por excesiva onerosidad o imposibilidad en su ejecución. Barcelona: Editorial Bosch. 